\title{
Open Access Publishing: What Authors Want
}

\section{Rajiv Nariani and Leila Fernandez}

\begin{abstract}
Campus-based open access author funds are being considered by many academic libraries as a way to support authors publishing in open access journals. Article processing fees for open access have been introduced recently by publishers and have not yet been widely accepted by authors. Few studies have surveyed authors on their reasons for publishing open access and their perceptions of open access journals. The present study was designed to gauge the uptake of library support for author funding and author satisfaction with open access publishing. Results indicate that York University authors are increasingly publishing in open access journals and are appreciative of library funding initiatives. The wider implications of open access are discussed along with specific recommendations for publishers.
\end{abstract}

"An open-access fund is a pool of money set aside by an institution to support publication models that enable free, immediate, online distribution of, and access to, scholarly research." 1

According to the Open Access Directory, there are thirty institutions to date with existing open access (OA) journal funds. ${ }^{2}$ The Compact for Open-Access Publishing Equity (COPE), in which fourteen North American institutions are participants, shows a commitment to this approach. COPE, which began in 2009 , is a response to a call by Shieber to institutions to help sustain open access publishers that do not have access to the traditional funding streams of subscription journals. By subsidizing article processing fees for OA journals, universities and funding agencies can provide equitable support for the business model for open access journals. This would place the subscription and article processing-fee models on a more level playing field. ${ }^{3}$ Within COPE, each signatory institution undertakes "the timely establishment of durable mechanisms for underwriting reasonable publication charges for articles written by its faculty and published in feebased open-access journals and for which other institutions would not be expected to provide funds." ${ }^{4}$ Six of the fourteen signatories have signed on since September 2010, suggesting that there is increasing support for this approach.

The Association for Research Libraries Scholarly Publishing and Academic Resources Coalition (ARL-SPARC) Web site includes resources for institutions contemplating open access author funds. ${ }^{5}$ At this site, Tananbaum has created a guide entitled "Campus-Based Open-

Rajiv Nariani and Leila Fernandez are Science Librarians in Steacie Science E Engineering Library at York University; e-mail: rajivn@yorku.ca, leilaf@yorku.ca. The authors would like to commend the York Libraries administration for their wholehearted support of Open Access initiatives at York. (C Rajiv Nariani and Leila Fernandez. Attribution-NonCommercial (http://creativecommons.org/licenses/by-nc-sa/3.0/) CC BY-NC 
Access Publishing Funds: A Practical Guide to Design and Implementation," covering the complexities involved in developing an OA author fund. ${ }^{6}$ Eckman and Weil of the University of California, Berkeley point to the Berkeley Research Impact Initiative and provide reasons for funding Berkeley researchers to publish OA. According to these authors, this initiative will make Berkeley research accessible, promote author rights retention and encourages the use of new and innovative scholarly publishing outlets. It will also support OA authors for whom cost is a barrier. $^{7}$

Publishing in open access journals is commonly referred to as gold OA, in contrast to green $\mathrm{OA}$, which embraces self-archiving of final peer-reviewed manuscripts in an institutional or disciplinary repository. ${ }^{8}$ York University Libraries support both forms of OA publishing. The libraries maintain an institutional repository as well as provide support for OA authors through institutional memberships. Memberships include BioMed Central (BMC) since 2005 and, more recently, Public Library of Science (PLoS) and Hindawi. Author processing charges are wholly or partially subsidized through these memberships. Faculty requests have been the driving factor in library support of OA journals, but publisher reputations have also been considered before committing to membership. Our present investigation is directed at studying the uptake of these author funding initiatives and determining the reasons for publishing OA with a view to identifying campus OA champions.

\section{Literature Review}

There have been a few studies of author perceptions on publishing in OA journals. Some early studies shed light on several factors, which may influence authors to publish OA. In a study of senior international authors, Rowlands, Nicholas, and Huntington show that very few authors $(11 \%)$ had experience publishing in an OA environment and appeared to want "free access at both ends of the chain: as authors and readers." Moreover, they seemed resistant to the idea of author payment. ${ }^{9}$ In a later survey of international authors, Swan and Brown list the lack of reputation and prestige as one of the factors that prevent authors from publishing in OA journals. Lack of funding and promotion and tenure issues were other concerns for these authors. Authors who had published OA had numerous reasons for publishing including support for the principle of open access, particular advantages such as speed of publication, the most suitable vehicle, objection to commercial publishers/serials crisis and copyright retention. ${ }^{10}$

Later disciplinary studies are also revealing of authors' attitudes to OA publishing. A study of British Medical Journal author perceptions of open access publishing was based on telephone interviews conducted to determine their motivations. Results indicated that almost all respondents supported the concept of OA publishing and were aware of its benefits. However, they showed a dislike of author charges in the absence of institutional support and were concerned about its implications for authors from developing countries and other unfunded authors. Many respondents said that they would continue to submit to high-quality journals even if there were charges. ${ }^{11}$ Warlick and Vaughan interviewed biomedical faculty on two U.S. campuses to understand motivating factors that led them to publish in open access/free full-text journals. Incentives and disincentives to publish were identified, and, for the most part, respondents were well-funded, paid publication charges and did not identify this as a concern. ${ }^{12}$

Most recently, a survey by Coonin and Younce covered authors publishing in open access education journals to determine their perspectives on OA publishing. When queried about publications that required author fees, a majority of the respondents (56.1\%) said that they would not publish in journals that required a 
publication fee, while 27 percent said that they would do so if a funding agency or institution paid for it. The authors of this study underline the fact that this is not a common practice among education publications, and some of the respondents equated author publication fees with vanity publishing. Unlike earlier studies, a substantially large number of authors associated prestige with OA journals. ${ }^{13}$ Russell and Kent from the University of Birmingham recently assessed the impact of OA in a case study of funded researchers who had institutional support for both green and gold access routes. They explored the motivations for researchers to choose OA and have concluded that researchers are not concerned about the business model and are solely interested in publishing their work in high-profile journals. ${ }^{14}$

The results from publisher-led studies provide further light on why authors chose to publish in OA journals and their acceptance of author charges. However, most of these studies are limited in scope and have focused on authors in specific journals. A survey by the editors of the Proceedings of the National Academy of Sciences showed a willingness on the part of half of author respondents to pay a surcharge (in addition to the page and color charges) for open access. ${ }^{15}$ In the case of Nucleic Acids Research, a survey of authors by the publisher indicated that OA would not be a deciding factor should they decide to publish their research in this journal. Impact factor, the journal profile and reputation, as well as the quality and speed of the peer-review process, would continue to be factors in making this decision. ${ }^{16}$ PLoS also conducted a survey of authors including those who had their papers rejected. Their study assessed author satisfaction with PLoS journals and the editorial process. The most popular reasons for submission to PLoS were journal quality, impact factor, OA, quality of PLoS brand, speed, and peer-review criteria. Price did not seem to be an issue and most users were "neutral" with respect to price. ${ }^{17}$ The results of the Study of Open Access Publishing (SOAP) project, a cross-disciplinary worldwide survey of authors conducted by a consortium of publishers, funding agencies, and libraries, were published most recently. Although the study was wider in scope than any of the previous studies and highlighted disciplinary differences, it did not provide substantially new insights. Results indicate "overwhelming support for the idea of open access, while highlighting funding and (perceived) quality as the main barriers to publishing open access." 18

Different approaches have been suggested to address the issue of OA author funding. In a recent article, King suggests that there are potential savings to be obtained in the scholarly publishing system by moving to 100 percent federal funding of articles by U.S. scientists. ${ }^{19}$ Studies by Houghton and Swan indicate that there will be cost benefits in research and higher education in the United Kingdom if there is a flip to OA in the scholarly publishing system. ${ }^{20}$ Pinfield of the University of Nottingham believes that there is a need for institutions to pay author fees so that publishing open access is a "realistic possibility." He surveyed U.K. library directors and found few had "an institutionally coordinated approach to payment of per-article OA fees (such as a central fund)." He recommends key practical considerations for institutions that are developing policies and procedures on this issue. ${ }^{21}$

At York University, we felt the need to understand more closely authors' experiences with publishing in librarysupported OA journals. Our study was designed to explore motivating factors as well as satisfaction with the choice of OA publishers while reinforcing the library's role in supporting authors to achieve these ends.

\section{Methodology}

We conducted semistructured interviews of campus authors who published in 
BMC, PLoS, and Hindawi journals. We identified authors by searching Web of Science, Scopus, and PubMed. Authors were given an option to use an online survey as an alternative only when they were unable to be present for an interview. We sent a link to an online survey that replicated the interview questions to participants. In all, we contacted thirtytwo faculty authors. Twelve responded to our request for an interview, and eight completed the online questionnaire, with a combined response rate of 62.5 percent.

We excluded graduate students, postdoctoral researchers, and those who had left the university. We did not seek to interview primary authors only; four of the twenty respondents were coauthors. We identified this by searching databases, institutional Web pages at publishers' Web sites, and publisher-supplied data on funded authors. Surveyed authors also provided journal titles for their OA publications. Eight authors were found to have published unique OA articles.

Limitations of the study are the small sample size and the possibility that authors who responded to our invitation to participate may already be predisposed toward open access. The study also provided us with teaching moments to educate faculty on topics related to OA and library resources. We were careful to provide answers to their questions after the interview so as not to influence their responses during the interview.

We carried out this study over a sevenmonth period from January through July 2010. The Human Participants Review Committee of the university approved our study protocol and questionnaire. We documented responses on paper and recorded conversations after seeking participants' consent. We report the results here by theme, combining findings from the interviews and responses to the online survey. A copy of the questions is included as an appendix.

\section{Results}

\section{Profile of Participants}

The participants were twenty faculty members from different departments including Biology (five), Business (one), Chemistry (one), Health Policy and Management (two), Kinesiology and

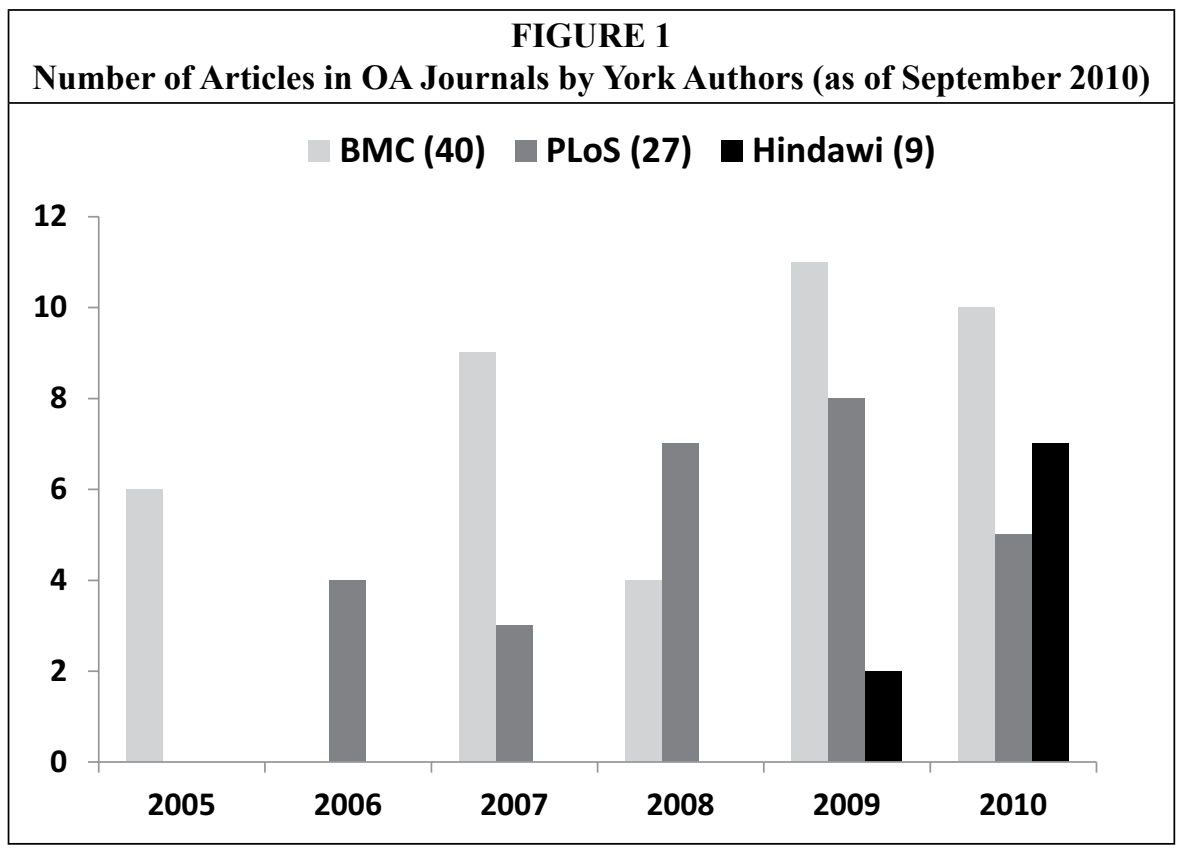


Health Sciences (five), Linguistics (one), Mathematics and Statistics (three), Neuroscience (one), Physics (one).

Faculty members had a wide range of research experience ranging from five years to fifty years, with a median of sixteen years. We did not ask them to identify themselves by rank or tenure status; however, from their Web sites we determined their designations as Assistant Professors (eight), Associate Professors (five), Full Professors (four), Contract Faculty (two), and one University Professor Emeritus.

Of the twenty respondents, twelve faculty members had published more than once in an open access journal. We were able to identify their publications by searching databases including Scopus, PubMed, and Web of Science, as well as institutional Web pages at publishers' Web sites. Journal publication titles provided by authors in the survey responses and data supplied by publishers on funded authors were also used in this analysis.

A total of seventy-six articles were published by York authors in supported OA journals by the end of our study (figure 1). Commentaries, book reviews, debates, or poster presentations are not included in this tally. Many of these articles were published in narrowly defined subject specialty journals with titles reflecting subjects such as arthritis, health geographics, health equity, head and neck oncology, reproductive endocrinology, infectious diseases, pregnancy, neuroengineering, and neuroinflammation.

\section{Factors involved in the Selection of OA Journals}

Researchers were asked how they became aware of OA journals and the reasons for publishing in them. Responses indicated that they had read articles in these journals or recognized familiar names on the editorial board. Some mentioned that the focus of the journal closely matched their subject interests or was being read by their peers. Other researchers mentioned that the journal was recommended by their colleague or submissions were solicited by the editor. Five participating York authors were on the editorial boards of OA journals or were involved in the initial planning stages of an OA journal.

Editorial policy was cited by more than one researcher as a reason for moving to PLoS. The changing focus of a neurophysiology journal based on the chief editor's interest in genetics prompted one researcher to look elsewhere for a place to publish. Another researcher decided to publish in PLoS Medicine because they accepted health policy-related systematic reviews, whereas another major journal declined because it did not match their publishing criteria.

\section{Journal Reputation}

Impact factor of the journal and subject area were the most common considerations while choosing an OA journal. Faculty wanted to publish in the journals with the widest exposure and that were being read by their colleagues. Other factors, like funding agency policy on Open Access, were also taken into account. Three of the respondents pointed out that the quality of the research results usually dictates where to publish. Two others mentioned that they chose to publish in open access journals when collaborating with graduate students. Others noted that impact factors of OA journals had steadily increased over time and were now comparable to high profile journals. A couple of faculty respondents stated that there are grammatical errors in certain peer-reviewed OA journals and that the quality of some OA journals needs to be improved. However, they acknowledged that this was a gradual process.

\section{Readership}

Collaboration with international authors was found to be a factor in the choice of an OA journal. One faculty member doing research on emerging diseases decided to publish in a BMC journal at the suggestion of her collaborators from a developing country. This would give 
other researchers in that country an opportunity to read the paper. According to the same author, North America-based subscription journals were not in favor of publishing research from developing countries since it did not align with their scope and objective. In another instance, a health science researcher, whose research has been focused on native communities in Ontario, wanted her paper to be read by aboriginal community researchers and hence decided to publish in an OA journal. The same author mentioned that she has started collaborating with researchers from Malaysia after reading their article in a BMC journal. Another respondent was invited to contribute to a special issue and agreed because he knew some of the contributing authors. In this case, OA was not the primary reason for publishing in this journal, but exposure of his work to others working in the same field was important.

\section{Speed of Publication}

Three-fourths of our respondents identified turnaround time as an important factor in the choice of an OA journal. Two respondents commented that speed of publication was not something unique to OA publishers, as most journals have now improved their turnaround time.

"Constant reminders and timely comments from the reviewers helped me in completing the article by the deadline and the article was published faster than I had anticipated!"

$\sim$ Business Faculty Member

\section{Indexing of $\mathrm{OA}$ Journals}

Indexing of OA journals in PubMed, Scopus, Web of Science, or other disciplinary databases was deemed very important by all our respondents. There were instances when PLoS articles had not yet been indexed in PubMed in a timely fashion, and at least one researcher found this unacceptable.

\section{Barriers to Publishing OA}

\section{Article Processing Charges}

We asked respondents to identify barriers to publishing in OA journals to see if costs associated with publishing would be a factor. The responses showed a divergence in attitudes to costs, with some faculty members, having been exposed to page charges, more accepting of costs for publishing. A few respondents had used their grant money to pay for article processing charges and did not consider cost as an issue. Others mentioned that they would not have published without library support.

“We shouldn't be charged anything. The publishers make money by other sources, they should not make money on the backs of the authors. In fact, they should pay us a nominal fee-without us, they would not have anything to publish."

$\sim$ Kinesiology \& Health Sciences Researcher

In the light of previous studies showing researchers' negative attitudes to publication charges, we probed further to see if respondents had paid page charges or publishing costs for color. In the case of library-supported OA journals, there are no additional fees apart from article processing costs. Biology researchers appeared to be quite familiar with page charges and did not consider article processing charges for OA journals excessive. The fact that there are no page limits was mentioned by a few respondents. We also tried to gauge whether cost-sharing is the norm in the publication process and were surprised that, in most cases, it is the primary author or the grant recipient who covers publication expenses.

\section{Career Advancement}

We asked if publishing in OA journals could be detrimental to tenure and promotion decisions. Responses indicated that publishing in OA journals would not be considered in a negative light by tenure 
and promotion committees. Granting councils acceptance of OA publishing was mentioned by more than one respondent as providing legitimacy for publishing in OA journals.

"The department does not have any
policy cautioning authors about
wider exposure and higher citations
to their OA articles and therefore
publishing in OA journals should
not be viewed as a barrier in tenure
and promotion!" Neuroscience Faculty Member

\section{Special Features of OA Journals}

Prior to our discussions with faculty, we identified some publishing features that are characteristic of OA journals and asked researchers about the relative importance of these features. These features are arranged in order of decreasing importance to authors (figure 2) and are described below.

Not all authors were familiar with the ability to attach supplementary data to the article. For biologists this was not a new feature, as some subscription journals offer this capability. However, more than half of our respondents thought it was important and appreciated this feature in OA journals.
Some of the interviewed authors sought clarification on the meaning of open peer-review. We explained that open peer-review provides disclosure of the identities of referees. This feature appeared to be acceptable to half of our respondents. One respondent found open peer-review problematic since it could lead to animosity between the reviewer and the submitting author if the article was rejected. Another researcher had heard that reviewers in OA journals were young and that peer-review was not as stringent; he was glad to learn that his paper was reviewed by a senior researcher. He was aware of this through the open peer-review process. In contrast, one of our respondents thought that the peerreview process for his publication was "superficial." Another mentioned that, if she was a reviewer, she would not be "as harsh" if she was identifiable; yet another was not convinced that open peer-review "improves the process."

Half of the respondents thought that publisher-provided statistics such as download data were important. More than one respondent mentioned that publishers should send them monthly statistics on article downloads and citations so that they do not need to check Web sites themselves.

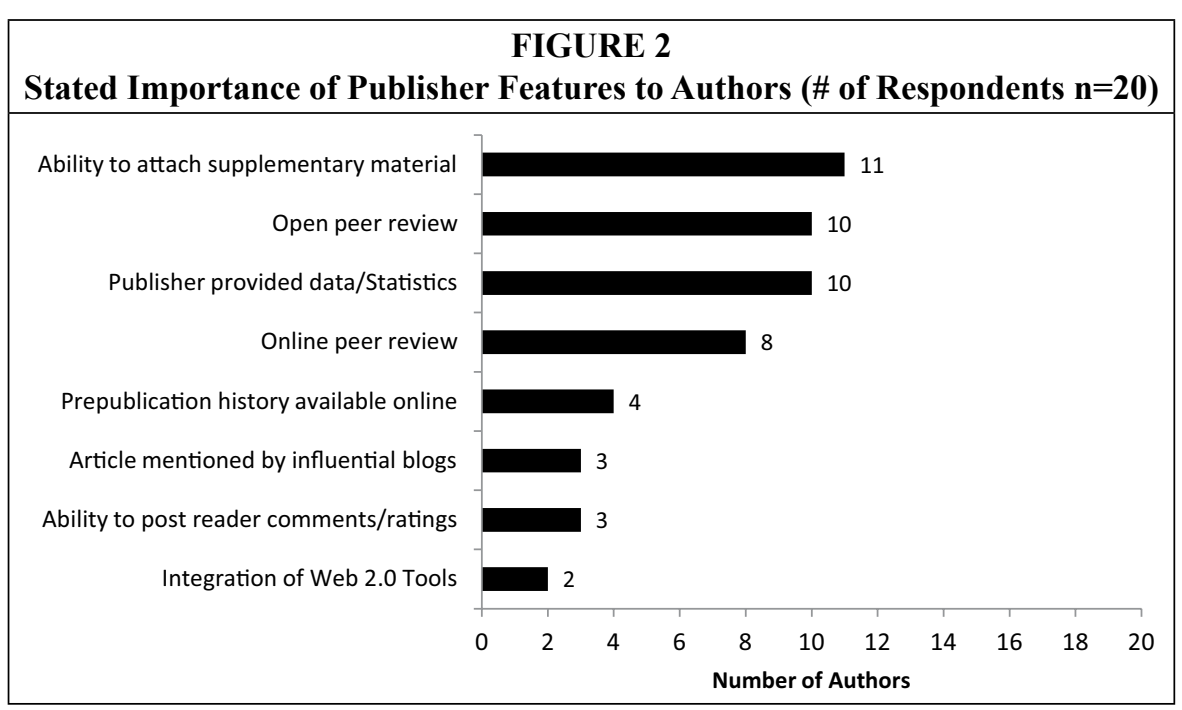


We explained online peer-review, also called post-publication peer-review, as the online posting of comments by peers at the publisher's Web site. Less than half of our respondents were enthused by this feature. Only one author was appreciative of this feature because it allowed "critical appraisal" of the work. Another was skeptical about this approach; yet another felt it was liable to misuse if anyone could post comments. Most were unaware of this facility and we demonstrated this feature wherever possible. One of the OA publishers being assessed provides open access to versions of the articles during the refereeing process. Our questions referred to this facility, which we called prepublication history. A majority of our respondents considered this feature unimportant (see figure 2).

When asked about posting of comments on the article in influential blogs, three of our respondents were positive about this feature. One of the respondents indicated that he would welcome this feature if it came from a highly regarded journal for, to give a couple of examples, Nature or Science blogs. Reader ratings also did not appeal to our respondents. Even less appreciated were the Web 2.0 tools such as Facebook, Twitter, and Connotea, which publishers are introducing to attract Web-savvy users. In fact, one of the respondents said that he had no time for this but was of the opinion that these tools may be used by his graduate students.

Copyright pertains to the exclusive rights to publish and distribute a work. Most OA journal publishers, unlike traditional subscription journals, do not require authors to surrender copyright. These publishers generally offer a choice of creative commons licenses. Comments by respondents concerning author rights show that at least some faculty members understand that copyright ownership could provide more control over their publications. One researcher took it for granted that creative commons licensing should go "hand-in-hand with OA."
Another showed awareness of the advantages to be gained in not relinquishing copyright.

"I like OA journals because anyone can download these papers and I can use them as examples for teaching purposes. Students don't need to pay for it."

\section{$\sim$ Kinesiology \& Health Sciences} Researcher

\section{Awareness of York Initiative to Support OA Publishers}

We wanted to ascertain whether authors were aware of the library initiative to support selected OA publishers and how they were informed of this. This could have implications on how library initiatives are best promoted. Five respondents mentioned that they became aware of library subsidies through librarians; others were informed after acceptance of their article by publishers. Half of our respondents had used library support for article processing fees. On the whole we found respondents, particularly junior faculty members, were overwhelmingly appreciative of library subsidies for article processing fees.

"York Libraries has by far done one of the best things by supporting OA publishers and paying author charges. Keep it up!"

\section{$\sim$ Kinesiology $\mathcal{E}$ Health Sciences}

Researcher

All authors except one said that they would continue to publish in open access journals. A couple of authors had used grant money to fund publication charges. Others mentioned that the decision to publish was taken by the principal author who paid the publication charges and that they concurred with the decision to publish open access. Among those who claimed funding, all except one mentioned that they would continue to publish open access as long as the library supported publication charges. One au- 
thor who was interviewed was not aware of funding mechanisms for supporting open access publishing. He mentioned he was not directly involved in the decision on where to publish but left it to the principal investigator. This author emphasized the importance of the physical library and the need for a balance between print and online. He expressed concern for the preservation of electronic-only content. The survey provided us with an educational opportunity to explain the rationale behind open access and library funding of open access publishing.

A visual representation of author perceptions and the factors involved in the selection of OA journals has been summarized below:

\section{Discussion}

The main points to emerge from our author survey were as follows:

1. Authors want to be read and cited by their peers. During our interviews, authors appeared to know about OA journals from reading articles in these journals or through discussions with their peers. The journals they selected matched both their subject interests and their targeted audience.

2. Journal impact factor was important to our respondents. Impact factor was a term frequently used, although many OA journals have not yet received an impact factor. PLoS has moved away from the impact factor and is looking at alternative metrics but our authors were unaware of these developments.

3. Authors in our study mentioned improvement in quality and wider dissemination as reasons for publishing in open access journals and appeared to be satisfied with the journals they had selected.

4. Authors were also interested in having their articles indexed in major Science Technology and Medicine databases such as PubMed and other disciplinary indexing services.

5. Publishing in an OA journal was not considered a barrier in the tenure and promotion process.

6. Authors showed a lack of awareness and appreciation for the special features that OA publishers are providing for their journals.

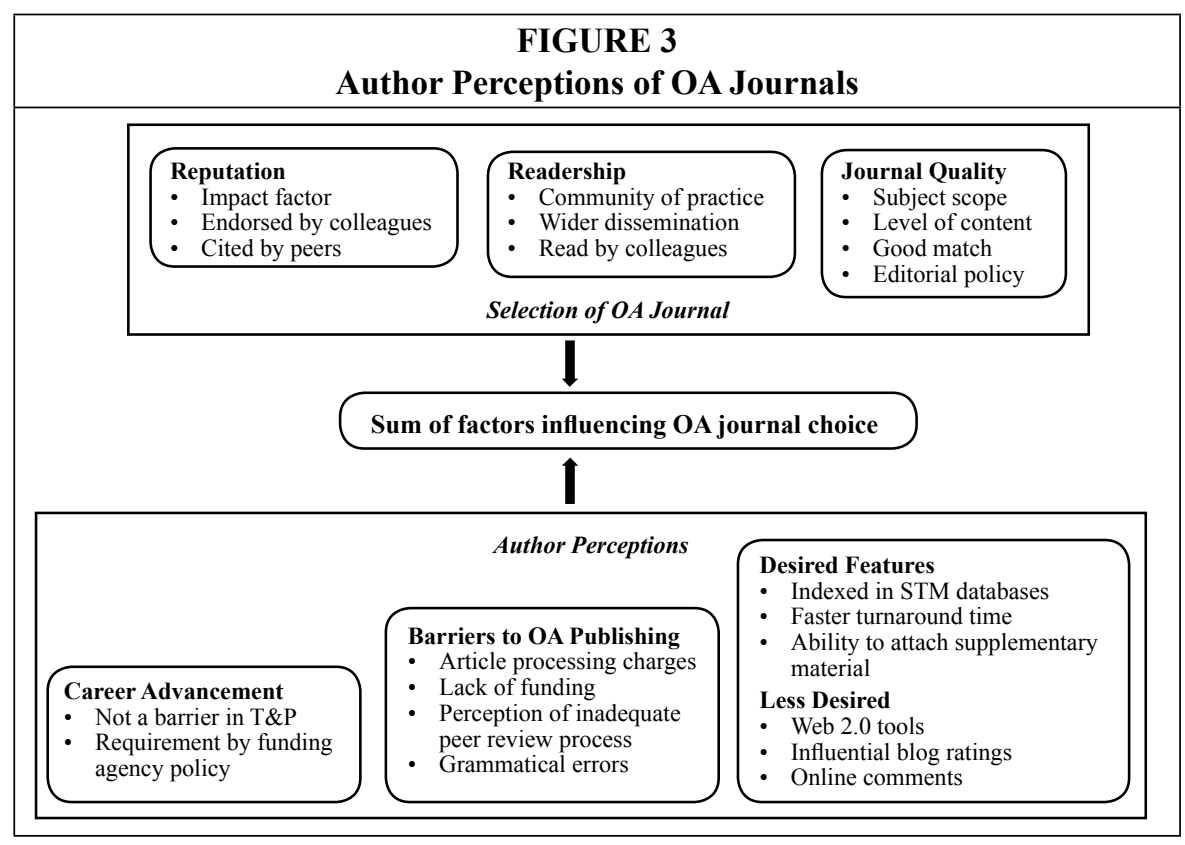


Promotion and tenure considerations do not appear to be barriers for York OA authors who participated in this study. This is in contrast to concerns voiced by authors in earlier studies where publishing in OA journals is seen to be detrimental to the academic reward system. ${ }^{22}$ However, our results are consistent with the study by Warlick and Vaughan where only one participant had career concerns. ${ }^{23}$ Most of the respondents in our study stated that tenure and promotion criteria are departmental-specific and that their departments did not consider publishing in OA journals to be a barrier. Participants were mostly mid-career to senior in status, with a median of sixteen years of research experience. This could have some bearing on their responses. Authors in our study were also aware that publishing in OA journals would comply with funder policies for public access. There are to date ten funders in Canada who have adopted public access policies for research outputs, and faculty understand the need to comply with these mandates.

We have examined publisher features as a motivating factor in OA publishing that has not yet been explored in other studies. Our results indicate that, although publishers are providing Web 2.0 approaches such as options for online commenting and integration with social media, researchers were not enthusiastic about these features. Lack of time and the inability to see value in these tools has limited their uptake. Publishers need to promote these tools and assure researchers that commenting features will not be misused. Neylon and Wu have examined the reasons for the failure of online commenting to gain traction; they state that the lack of incentives or "reward for quality contribution" could be one of the contributing factors. ${ }^{24}$ According to these authors, there is no credit system for postpublication commenting, and people making hiring and granting decisions do not consider this to be a valuable contribution.
The results of our study reinforce the observations made in some of the earlier studies where authors indicate that impact factor and readership are strong motivators for publishing. ${ }^{25}$ Indexing of articles in science databases is extremely important to our study participants. BMC and Hindawi provide impact factors and indexing policies for their journals, but this is not uniformly available for all their titles. PloS journals are indexed in major databases and emphasize alternative metrics instead of impact factors. In the recently conducted SOAP study, 30 percent of the respondents mentioned journal quality as one of the reasons for not publishing open access. ${ }^{26}$ The respondents in our study mentioned improving quality of OA journals and appeared to be satisfied with their choice of publication. All respondents except one said that they would continue to publish in open access journals.

\section{Recommendations for Publishers}

We have several recommendations for OA publishers based on faculty input. Timely indexing in PubMed and other databases is critical for researchers, since they are interested in faster dissemination of their work. Promotion of OA articles through press releases can highlight and create more visibility for their research. Researchers need to be provided access statistics on a regular basis to see that their work is being read and cited. Prominent display of articles by authors from member institutions is desirable, since it emphasizes institutional presence. Special features available with OA journals need to be better promoted and their usefulness demonstrated more clearly. Closer contact with liaison librarians can create awareness and help promote subject-specific OA journals.

\section{Promotion of Open Access Journal Publishing}

Promotion of open access funds is considered necessary to maximize the use of author funds. ${ }^{27}$ At York, we have 
promoted author funds widely through campus publishing outlets and events; as a result, we have seen an increase in the number of campus faculty who publish in open access venues. As a result, there has been increasing uptake of library funding for article processing charges. While promoting these journals, we have also received faculty requests for author funding to publish in nonsupported journals. Personal interviews gave us better insight into the attitudes and publishing behavior of our researchers compared to the online survey where the responses were to the point and offered little opportunity for further probing. Through these interviews, we were able to better address some of their misconceptions regarding open access publishing. In fact, library endorsement of OA journals can be important in assuaging some of their concerns. Occasionally, we were asked to explain the criteria used to support some OA journals and not others. Through our interviews, we were also able to gain insight into how faculty view the library and access library resources. Meeting with faculty also provided us with instructional opportunities. However, we were careful to confine these to the ends of the interviews so as not to influence participants' responses.

\section{Concluding Comments}

PLoS, BMC, and Hindawi are providing a wider selection of journals and are gaining recognition with York faculty. Since this study was completed, there have been an additional twenty-one articles published by York authors in journals from these publishers, approximately half of which have been reimbursed by the libraries. Five of these authors had already been interviewed by us; six were repeat authors. During our interviews, some authors mentioned that they would not have published without funding support. Our study shows that author funding can provide an incentive for York authors to publish in OA journals. Library funding is being allocated from the library's collections budget. We are aware that increasing uptake of library funds may require fine-tuning or development of a policy for author support. A formal policy can help an institution define limits for OA funding in the interest of sustainability.

Sustainability of OA funds is a concern for many libraries. A recent blog posting by Shieber based on statistics of OA fund expenditures from COPE signatories estimates that the approximate cost per faculty member is minimal..$^{28}$ Results of the SOAP study indicate "overwhelming support" for open access, while highlighting funding as one of the main barriers to publishing open access. ${ }^{29}$ For libraries that are concerned about sustainability, prorating or shared support between authors and institutional funds may be more viable options. COPE signatories have provided details of their OA funding policies with examples of exclusions: for instance, withholding funding to grantfunded authors. ${ }^{30}$ The inability to predict uptake of author funds is an issue that has been discussed by Pinfield. He has suggested that libraries review their funding policies on a regular basis, with an eye toward looking for ways to streamline administration of funds. ${ }^{31}$

At York, we are increasing the visibility of OA journals by including them in our eresources database and providing access through our link resolver. In the future, we plan to monitor usage patterns to see if library-supported OA journals are being read by our user community. Usage can help us understand how important these journals are to our users. As librarians, we also need to educate our researchers on new scholarly communication models and the benefits they provide. Alternative publishing metrics and new approaches to peer review are part of this landscape. It is encouraging that $\mathrm{OA}$ journals are achieving greater prominence; however, if we are going to create change in the scholarly publishing system, we need to allocate more resources in this direction. 


\section{Appendix \\ OA Questionnaire}

\section{General}

1. What is your area of research?

2. For how many years have you been conducting research?

\section{Choice of journal}

3. Have you published in an OA journal?

4. How did you hear about this journal?

$\square$ Known editor $\square$ Colleagues $\square$ Advertisement/Promotion

5a. Factors influencing your decision to choose an OA journal.

$\square$ Impact factor $\square$ Turnaround time $\square$ Open peer-review $\square$ Online peer-review $\square$ Community practice/Unique in its field/Matched your research interests

$\square$ Articles in journal read by colleagues

$5 b$. Which of the following features did you find important?

$\square$ Publishers supply access information/Data statistics on your articles

$\square$ Social/Web 2.0 tools like RSS feeds, Export to Facebook, Twitter, Connotea, etc

Article indexed in PubMed/Scopus/Web of knowledge

$\square$ Prepublication history

Link from publisher Web site to PubMed/Google Scholar

Ability to attach supplementary data

Ability to post comments/reader ratings

$\square$ Mention by influential blogs

6. Do author fees/page charges influence your choice of journals? Have you ever paid charges for color pages, audio files, or other features?

$\square$ How much would you pay?

Are processing fees a factor when you are deciding to publish in OA journals?

7. Would you consider publishing in OA journals being a factor in the tenure \& promotion process?

8. What are the barriers to publishing in OA journals?

9. Were you aware of the YUL initiative of subsidizing Article Processing Charges $(\mathrm{APC})$ ? Did you avail this option?

10. Would you continue to publish in OA journals with subsidized APC?

11. Do you have any suggestions for other publishers who may be supported by the libraries?

\section{Collaborate/Sharing}

12. Are you collaborating with other researchers? Does this influence your choice of journal?

13. How would you distribute the APC in case of multiple authors? 


\section{Additional Questions:}

\section{Would you consider publishing again in an OA journal?}

15. Is there anything else you would like to add?

\section{Notes}

1. Scholarly Publishing \& Academic Resources Coalition, Association of Research Libraries, Campus-based Open-access Publishing Funds, available online at www.arl.org/sparc/openaccess/ funds/ [accessed 8 August 2010].

2. Open Access Directory, OA Journal Funds, available online at http://oad.simmons.edu/ oadwiki/OA_journal_funds [accessed 8 August 2010].

3. Stuart M. Shieber, "Equity for Open-Access Journal Publishing," Plos Biology 7 (Aug. 2009), available online at www.plosbiology.org/article/info:doi\%2F10.1371\%2Fjournal.pbio.1000165 [accessed 10 August 2010].

4. COPE, Compact for Open-Access Publishing Equity, available online at www.oacompact.org/ compact/ [accessed 8 August 2010]. Funds.

5. Scholarly Publishing \& Academic Resources Coalition, Campus-based Open-access Publishing

6. Greg Tananbaum, Campus-based Open-access Publishing Funds: A Practical Guide to Design and Implementation, available online at www.arl.org/sparc/openaccess/funds/guide.shtml [accessed 10 August 2010].

7. Charles D. Eckman and Beth T. Weil, "Institutional Open Access Funds: Now Is the Time," Plos Biology 8, no. 5 (May 2010), available online at www.plosbiology.org/article/ info\%3Adoi\%2F10.1371\%2Fjournal.pbio.1000375 [accessed 10 August 2010].

8. Stevan Harnad, Open Access, available online at www.eprints.org/openaccess/ [accessed 14 August 2010].

9. Ian Rowlands, Dave Nicholas, and Paul Huntington, "Scholarly Communication in the Digital Environment: What Do Authors Want?" Learned Publishing 17, no. 4 (Oct. 2004): 261-73.

10. Alma Swan and S. Brown, "Open Access Self-Archiving: An Author Study,” (Truro, United Kingdom: Key Perspectives Ltd., 2005), available online at http://eprints.ecs.soton.ac.uk/10999/ [accessed 10 August 2010].

11. Sara Schroter, Leanne Tite, and Richard Smith, "Perceptions of Open Access Publishing: Interviews with Journal Authors," British Medical Journal 330, no. 7494 (Jan. 2005): 756-59.

12. Stefanie Warlick and K.T.L. Vaughan, "Factors Influencing Publication Choice: Why Faculty Choose Open Access," Biomedical Digital Libraries 4, no. 1 (Mar. 2007), available online at www. bio-diglib.com/content/4/1/1 [accessed 10 August 2010].

13. Bryna Coonin and Leigh M. Younce, "Publishing in Open Access Education Journals: The Authors' Perspectives," Behavioral and Social Sciences Librarian 29, no. 2 (2010): 118-32.

14. Jill Russell and Tracy Kent, "Paved with Gold: An Institutional Case Study on Supporting Open Access Publishing," Serials: The Journal for the Serials Community 23, no. 2 (July 2010): 97-102.

15. Nicholas R. Cozzarelli, Kenneth R. Fulton, and Dianne M. Sullenberger, "Results of a PNAS Author Survey on an Open Access Option for Publication," Proceedings of the National Academy of Sciences of the United States of America 101, no. 5 (Feb. 2004): 1111.

16. Claire Bird, "Continued Adventures in Open Access: 2009 Perspective," Learned Publishing 23, no. 2 (2010): 107-16.

17. Mark Patterson, PloS Author Research 2009, available online at www.slideshare.net/MarkPatterson/plos-author-research-2009 [accessed 10 August 2010].

18. Suenje Dallmeier-Tiessen and others, "Highlights from the SOAP Project Survey: What Scientists Think about Open Access Publishing," arXiv:1101.5260 (2011), available online at http:// arxiv.org/abs/1101.5260 [accessed 25 February 2011].

19. Donald King, "An Approach to Open Access Author Payment," D-Lib Magazine 16, no. 3-4 (2010), available online at www.dlib.org/dlib/march10/king/03king.html [accessed 10 August 2010].

20. John W. Houghton and Charles Oppenheim, "The Economic Implications of Alternative Publishing Models," Prometheus: Critical Studies in Innovation. 28, no. 1 (2010): 41-54; Alma Swan, "Modelling Scholarly Communication Options: Costs and Benefits for Universities," (Truro, United Kingdom: Key Perspectives Ltd., 2010), available online at http://eprints.ecs.soton.ac.uk/18584/1/ Modelling_scholarly_communication_report_final.pdf [accessed 10 August 2010]. 
21. Stephen Pinfield, "Paying for Open Access? Institutional Funding Streams and OA Publication Charges," Learned Publishing 23, no. 1 (Jan. 2010): 39-52.

22. Bo-Christer Björk, "Open Access to Scientific Publications: An Analysis of the Barriers to Change?" Information Research 9, no. 3 (Jan. 2004), available online at http://informationr.net/ir/92/paper170.html [accessed 14 August 2010]; Swan and Brown, "Open Access Self-Archiving: An Author Study."

23. Warlick and Vaughan, "Factors Influencing Publication Choice."

24. Cameron Neylon and Shirley Wu, "Article-Level Metrics and the Evolution of Scientific Impact," Plos Biology 7, no. 11 (Nov. 2009), available online at www.plosbiology.org/article/ info:doi/10.1371/journal.pbio.1000242 [accessed 10 August 2010].

25. Warlick and Vaughan, "Factors Influencing Publication Choice"; Swan and Brown, "Open Access Self-Archiving: An Author Study,"; Rowlands, Nicholas, and Huntington, "Scholarly Communication in the Digital Environment."

26. Dallmeier-Tiessen and others, "Highlights from the SOAP Project Survey: What Scientists Think about Open Access Publishing."

27. Tananbaum, Campus-based Open-access Publishing Funds.

28. Stuart Shieber, How Much Does a Cope-Compliant Open-Access Fund Cost? The Occasional Pamphlet (2010), available online at http://blogs.law.harvard.edu/pamphlet/2010/08/06/how-muchdoes-a-cope-compliant-open-access-fund-cost/ [accessed 9 August 2010].

29. Dallmeier-Tiessen and others, "Highlights from the SOAP Project Survey: What Scientists Think about Open Access Publishing."

30. "Compact for Open-Access Publishing Equity," available online at www.oacompact.org/ compact/ [accessed 10 August 2010].

31. Pinfield, "Paying for Open Access?" 47.

\section{informs subscription plans}

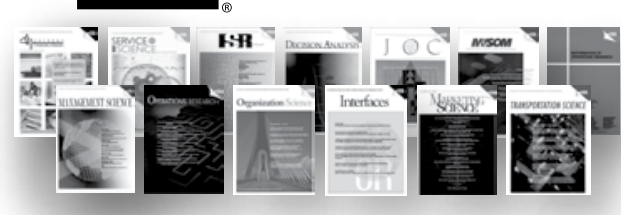

SERVICE OSCIENCE】

\section{NEW INFORMS Journal}

Driven by today's new business environment research in the service sector is creating new sources of innovation, collaboration, and value co-creation for people's satisfaction and success. Service Science, a fully refereed online-only journal, publishes state-of-the-art research, education, practice, and breakthroughs in the service science. http://servsci.pubs.informs.org

\section{Subscribe Today!}

Email: IPOLcentral@INFORMS.org

Phone: +1.800.4.INFORMs

www.informs.org/subscribe

\section{for libraries}

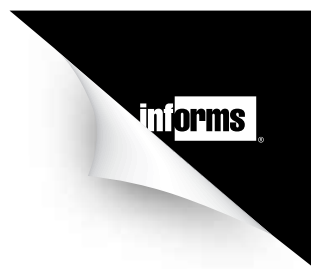

Pubs $\mathbb{A}$ Onesuite

Subscribe to the entire 13-journal package of INFORMS full-range of business and engineering journals covering operations research, management science, and analytics studies. You get print+online or online-only access to all 2012 content plus all online issues back through 1998.

- Save over $\$ 1,100$

- Remote \& campus wide access

- FREE 30-day trials available

www.informs.org/inst-pubssuite 